\title{
ANALISA KAPASITAS DIMENSI SALURAN DRAINASE DI JALAN KEBUN AGUNG SAMARINDA
}

\author{
Suharto \\ Dosen Program Studi Teknik Sipil Fakultas Teknik \\ Universitas 17 Agustus 1945 Samarinda \\ E-mail: hartosuharto1966@gmail.com / HP.082158068376
}

\begin{abstract}
ABSTRAK
Saluran drainase merupakan saluran air atau jalur pembuangan air untuk mengurangi kelebihan air. Saluran drainase direncanakan untuk menampung debit rencana dengan aman berdasarkan data curah hujan, tata guna lahan dan dimensi saluran. Saluran drainase di daerah tangkapan air hujan sepanjang jalan Kebun Agung Samarinda saat ini telah melebihi kapasitas tampungan, sehingga air meluap pada musim hujan dan akhirnya menimbulkan genangan di daerah sekitarnya. Oleh sebab itulah perlu dilakukan perencanaan ulang terhadap dimensi saluran drainase tersebut. Penelitian ini bertujuan untuk mengetahui kapasitas debit air saluran drainase existing serta kapasitas debit air dan dimensi saluran yang diperlukan pada kala ulang 5, 10, 25 tahun. Metode yang digunakan adalah metode distribusi frekuensi gumbel untuk menghitung curah hujan rencana dan metode rasional untuk menghitung debit air, kemudian menganalisa dimensi saluran terhadap debit air rencana pada kala ulang 5, 10, 25 tahun. Hasil analisa didapatkan dimensi saluran drainase dengan lebar 1,5 m dan pada setiap kala ulang 5, 10, 25 tahun, harus dilakukan peninggian drainase 1 meter per setiap kala ulang 5, 10, 25 tahun dari hasil debit rencana.
\end{abstract}

Kata kunci : saluran drainase, kapasitas, debit air

\section{ABSTRACT}

Drainage channels are drains or drainage channels to reduce excess water. The drainage channel is planned to accommodate the discharge plan safely based on rainfall data, land use and channel dimensions. The drainage channel in the rainwater catchment area at Kebun Agung Samarinda road has now exceeded the storage capacity, so that the water overflows in the rainy season and eventually creates inundation in the surrounding area. Therefore, it is necessary to re-plan the dimensions of the drainage channel. This study aims to determine the water discharge capacity of the existing drainage channels as well as the water discharge capacity and channel dimensions required at the 5, 10, 25 year return period. The method used is the gumbel frequency distribution method to calculate the planned rainfall and the rational method to calculate the water discharge, then analyze the dimensions of the channel to the planned water discharge at the 5, 10, 25 year return period. The results of the analysis obtained the dimensions of the drainage channel with a width of $1.5 \mathrm{~m}$ and at each return period of 5, 10, 25 years, the drainage should be raised 1 meter per each 5, 10, 25 year return period from the results of the planned discharge.

Key words: drainage channel, capacity, water discharge 


\section{PENDAHULUAN}

Kota Samarinda merupakan Ibu Kota Propinsi Kalimantan Timur yang secara astronomis terletak pada posisi antara $117^{\circ} 03^{\prime} 00^{\prime \prime}-117^{\circ} 18^{\prime} 14^{\prime \prime}$ Bujur Timur dan 00¹9'02" - 0042'34" Lintang Selatan, dengan ketinggian $10.200 \mathrm{~cm}$ diatas permukaan laut dan suhu udara kota antara $22-32^{\circ} \mathrm{C}$ dengan curah hujan mencapai $2.345 \mathrm{~mm}$ pertahun dengan kelembaban udara rata-rata 81,4\%. Berdasarkan kondisi hidrologinya Kota Samarinda dipengaruhi oleh sekitar 20 daerah aliran sungai (DAS). Sungai Mahakam adalah sungai utama yang membelah Kota Samarinda dengan lebar antara 300-500 meter.

Peristiwa Banjir akhir-akhir ini sering terjadi di wilayah Kota Samarinda, khususnya di jalan Kebun Agung yang merupakan salah satu daerah titik banjir yang ada di Samarinda. Pada saat hujan deras air yang mengalir di saluran drainase melebihi kapasitas tampungan saluran sehingga air meluap dan akhirnya menimbulkan genangan di daerah sekitarnya. Peristiwa banjir hampir setiap tahun berulang, namun permasalahan seperti ini masih belum bisa terselesaikan bahkan lebih cenderung makin meningkat permasalahannya. Jika musim hujan tiba masalah banjir menjadi ancaman serius pada beberapa titik banjir yang ada di Samarinda. Pasalnya pusat kota akan mengalami kerusakan oleh tingginya genangan air akibat luapan sejumlah permukaan sungai yang menenggelamkan sejumlah pemukiman padat penduduk.

Pertambahan penduduk mempengaruhi perkembangan kota yang menimbulkan dampak terhadap drainase perkotaan, sebagai contoh perkembangan kawasan hunian yang tidak diimbangi dengan sistem drainase yang baik akan menjadi salah satu penyebab terjadinya banjir, serta perubahan penggunaan lahan yang seharusnya menjadi daerah resapan di sepanjang Sungai Mahakam berubah menjadi pemukiman sehingga berakibat adanya pendangkalan sungai Mahakam. Ditinjau dari permasalahan diatas, perlu adanya analisa ulang terhadap dimensi saluran drainase yang merupakan salah satu faktor penyebab terjadinya banjir. Sehingga dapat diketahaui kapasitas saluran tersebut memadai atau tidak dalam menampung debit air hujan tanpa menimbulkan genangan air maupun banjir.

\section{TINJAUAN PUSTAKA}

\section{Saluran Drainase}

Drainase yang berasal dari bahasa inggris yaitu drainage mempunyai arti mengalirkan, menguras, membuang, atau mengalirkan air. Dalam bidang teknik sipil, drainase secara umum dapat didefinisikan sebagai suatu tindakan teknis untuk mengurangi kelebihan air, baik yang berasal dari air hujan, rembesan, maupun kelebihan air irigasi dari suatu kawasan/ lahan, sehingga fungsi kawasan/lahan tidak terganggu. Drainase dapat juga diartikan sebagai usaha untuk mengontrol kualitas air tanah dalam kaitannya dengan sanitasi. Jadi, drainase menyangkut tidak hanya air permukaan tapi juga air tanah (Suripin, 2004).

Secara umum, sistem drainase dapat didefinisikan sebagai serangkaian bangunan air yang bsefungsi untuk mengurangi dan/atau membuang kelebihan air dari 
suatu kawasan atau lahan, sehingga lahan dapat difungsikan secara optimal. Dirunut dari hulunya, bangunan sistem drainase terdiri dari saluran penerima (interceptor drain), saluran pengumpul (collector drain), saluran pembawa (conveyor drain), saluran induk (main drain), dan badan air penerima (receiving waters). Disepanjang sistem sering dijumpai bangunan lainnya,seperti goronggorong, siphon, jembatan air (aquaduct), pelimpah, pintu-pintu air, bangunan terjun, kolam tando, dan stasiun pompa. Pada sistem yang lengkap, sebelum masuk ke badan air penerima, air diolah dahulu di instalasi pengolahan air limbah (IPAL), khususnya untuk sistem tercampur. Hanya air yang telah memenuhi baku mutu tertentu yang dimasukkan ke badan air penerima, sehingga tidak merusak lingkungan (Suripin, 2004).

\section{Distribusi Gumbel}

Dalam penggambaran pada kertas probabilitas, Chow (1964) menyarankan penggunaan rumus berikut ini.

Keterangan :

$$
X=\mu+\sigma k
$$

$$
\begin{aligned}
\mu & =\text { harga rata-rata populasi } \\
\sigma & =\text { standar deviasi (simpangan baku) } \\
\mathrm{K} & =\text { Faktor probabilitas }
\end{aligned}
$$

Apabila jumlah populasi yang terbatas (sampel), maka persamaannya sebagai berikut:

$$
\mathrm{X}=\overline{\mathrm{X}}+\mathrm{sK}
$$

Keterangan :

$$
\begin{aligned}
& \mathrm{X}=\text { harga rata-rata sampel } \\
& \mathrm{s}=\text { standar deviasi ( simpangan baku ) sampel }
\end{aligned}
$$

Faktor probabilitas $\mathrm{K}$ untuk harga-harga ekstrim Gumbel dapat dinyatakan persamaan sebagai berikut :

Keterangan :

$$
K=\frac{Y_{T_{r}}-Y_{n}}{S_{n}}
$$

$\mathrm{Y}_{\mathrm{n}}=$ reduced mean yang tergantung jumlah sampel/data $\mathrm{n}$

$\mathrm{S}_{\mathrm{n}}=$ reduced standart deviation yang juga tergantung pada jumlah sampel/data $\mathrm{n}$

Ytr $=$ reduced variate, yang dapat dihitung dengan persamaan berikut ini.

\section{Daerah Tangkapan Air (Catchment Area)}

Luas tangkapan air (Catchment Area) adalah daerah pengaliran yang menerima curah hujan selama waktu tertentu (Intensitas Hujan) sehingga menimbulkan debit limpasan yang harus ditampung oleh saluran hingga mengalir ke ujung saluran (outlet).

Untuk menghitung luas area tangkapan air dapat digunakan rumus :

$$
A=\frac{1}{2}\left(X 1 . Y 2+X 2 . Y 3+\ldots+X_{n} . Y_{n+1}-Y 1 . X 2-Y 2 . X 3-\ldots-Y_{n .} X_{n+1}\right)
$$


Dimana :

A $\quad=$ Luas area $\left(\mathrm{km}^{2}\right)$.

$\mathrm{X} 1, \mathrm{X} 2, \mathrm{X} 3, \mathrm{Xn} . . . . .=$ Titik kordinat sumbu $\mathrm{x}$ yang ditinjau dari topografi peta.

$\mathrm{Y} 1, \mathrm{Y} 2, \mathrm{Y} 3, \mathrm{Yn} . . . .$. = Titik kordinat sumbu y yang ditinjau dari topografi peta

\section{Debit Air Rencana}

Debit rencana untuk daerah perkotaan umumnya dikehendaki pembuangan air yang secepatnya, agar tidak terjadi gangguan air yang berarti. Untuk memenuhi tujuan ini, saluran - saluran harus dibuat cukup sesuai debit rencana. Suatu daerah perkotaan umumnya merupakan bagian dari suatu daerah aliran yang luas dan daerah ini sesudah memiliki drainase alami diperlukan perencanaan dan agar keadaan aslinya dapat dipertahankan sebaik mungkin.

Debit rencana adalah penjumlahan dari debit air hujan dengan debit air buangan penduduk yaitu dengan rumus :

$\mathrm{Q}=0.002778$. C.I.A (bila A dalam satuan hektar) atau

$\mathrm{Q}=0.278$.C.I.A (bila A dalam satuan $\mathrm{Km}^{2}$ )

Keterangan :

$$
\begin{array}{ll}
\mathrm{Q} & =\text { Debit Air Hujan }\left(\mathrm{m}^{3} / \mathrm{dtk}\right) \\
\mathrm{C} & =\text { Koefisien Limpasan Pengaliran } \\
\mathrm{I} & =\text { Intenssitas Curah Hujan }(\mathrm{mm} / \mathrm{jam}) \\
\mathrm{A} & =\text { Luas daerah pengaliran }\left(\mathrm{km}^{2}\right. \text { atau Ha) }
\end{array}
$$

\section{Perhitungan Dimensi Saluran Penampang basah bedasarkan debit air dan} kecepatan

Rumus :

Keterangan :

$$
\mathrm{A}=\mathrm{Q} / \mathrm{V}
$$

$\mathrm{A}=$ Luas penampang berdasarkan debit air dan kecepatan $\left(\mathrm{m}^{2}\right)$

$\mathrm{Q}=$ Debit Air $\left(\mathrm{m}^{3} /\right.$ detik $)$

$\mathrm{V}=$ Kecepatan Aliran ( $\mathrm{m} /$ detik )

\section{METODE PENELITIAN}

Metode yang digunakan dalam penelitian ini terdiri dari dua tahapan yaitu tahap pertama melakukan survey kondisi saluran drainase di daerah penelitian, yang menurut masyarakat sering terjadi luapan air ketika hujan turun. Tahap kedua inventarisasi data-data pendukung seperti data curah hujan harian Kota Samarinda selama 10 tahun yaitu dari tahun 2009 sampai tahun 2018, dari BMKG Kota Samarinda, peta topografi atau rupa bumi dari Badan Koordinasi Survei dan Pemetaan Nasional (BAKOSURTANAL).

\section{Lokasi Penelitian}

Lokasi penelitian berada di jalan Kebun Agung, Lempake Kecamatan Samarinda Utara. Daerah ini merupakan salah satu pusat kegiatan perekonomian, sehingga berdampak pada pertumbuhan penduduk dan perubahan tata guna lahan yang 
memberikan konstribusi pada perubahan limpasan dan debit, terutama dimusim hujan sehingga berpengaruh pada kapasitas tampung saluran drainase jalan Kebun Agung.

\section{Tahapan Analisa}

Analisa dilakukan dengan menggunakan metode distribusi frekuensi gumbel untuk menghitung curah hujan rencana dan metode rasional untuk menghitung debit air kemudian menganalisa dimensi saluran terhadap debit air rencana pada kala ulang 5, 10, 25 tahun.

\section{HASIL DAN PEMBAHASAN}

\section{Pengolahan Data Curah Hujan}

Dalam penelitian ini dipakai data curah hujan harian kota Samarinda dari stasiun pencatat curah hujan Bandara Temindung kota Samarinda mulai tahun 2009 sampai dengan tahun 2018 (10 tahun) yang disajikan pada tabel 4.1. Dalam pengolahan data curah hujan ini digunakan curah hujan harian maksimum (mm) tiap tahunnya.

Tabel 1. Data Curah Hujan Harian Rata - Rata

\begin{tabular}{|c|c|c|}
\hline No & Tahun & Curah Hujan Harian Maks. \\
\hline 1 & 2009 & 381.3 \\
\hline 2 & 2010 & 298.4 \\
\hline 3 & 2011 & 446.8 \\
\hline 4 & 2012 & 295.0 \\
\hline 5 & 2013 & 212.2 \\
\hline 6 & 2014 & 210.0 \\
\hline 7 & 2015 & 299.5 \\
\hline 8 & 2016 & 302.5 \\
\hline 9 & 2017 & 427.3 \\
\hline 10 & 2018 & 332.9 \\
\hline
\end{tabular}

Distribusi Frekuensi Hujan Rencana Dengan Metode Gumbel

Dengan menggunakan metode distribusi frekuensi gumbel didapat hasil sebagai berikut :

Tabel 2. Perhitungan Curah Hujan Rencana Rata - Rata Dengan Metode Gumbel

\begin{tabular}{|c|c|r|c|r|r|r|r|}
\hline No. & Tahun & Hujan $(\mathrm{mm})$ & $\mathrm{Xi}$ & $(\mathrm{Xi}-\mathrm{X})$ & $(\mathrm{Xi}-\mathrm{X})^{2}$ & $(\mathrm{Xi}-\mathrm{X})^{3}$ & $(\mathrm{Xi}-\mathrm{X})^{4}$ \\
\hline 1 & 2009 & 381.3 & 381.3 & 60.7 & 3685.7 & 223759.1 & 13584414.7 \\
\hline 2 & 2010 & 298.4 & 298.4 & -22.2 & 492.4 & -10926.3 & 242453.9 \\
\hline 3 & 2011 & 446.8 & 446.8 & 126.2 & 15929.0 & 2010394.6 & 253731897.3 \\
\hline 4 & 2012 & 295.0 & 295.0 & -25.6 & 654.8 & -16757.6 & 428826.0 \\
\hline 5 & 2013 & 212.2 & 212.2 & -108.4 & 11748.4 & -1273408.2 & 138024716.9 \\
\hline
\end{tabular}


JURNAL KACAPURI

JURNAL KEILMUAN TEKNIK SIPIL

Volume 3 Nomor 2 Edisi Desember 2020

\begin{tabular}{|c|r|r|r|r|r|r|r|}
6 & 2014 & 210.0 & 210.0 & -110.6 & 12230.1 & -1352532.1 & 149576522.5 \\
\hline 7 & 2015 & 299.5 & 299.5 & -21.1 & 444.8 & -9380.6 & 197836.5 \\
\hline 8 & 2016 & 302.5 & 302.5 & -18.1 & 327.2 & -59119.9 & 107091.3 \\
\hline 9 & 2017 & 427.3 & 427.3 & 106.7 & 11387.0 & 1215109.3 & 129664317.9 \\
\hline 10 & 2018 & 332.9 & 332.9 & 12.3 & 151.5 & 1865.4 & 22963.2 \\
\hline \multicolumn{2}{|l|}{ Jumlah } & 3205.90 & & & & & \\
\cline { 1 - 4 } Rata -rata & 320.590 & & 0.00 & 57051.05 & 782203.78 & 685581040 \\
\hline
\end{tabular}

Jumlah data yang dipergunakan (n) $=10$

$>$ Jumlah nilai data

Nilai rata - rata

Standart deviasi (S)

$$
\begin{array}{ll}
= & 3205.90 \\
= & 320.590 \\
= & \frac{\sqrt{\sum(\mathrm{Xi}-\overline{\mathrm{X}})^{2}}}{(\mathrm{n}-1)} \\
= & \frac{57051.049}{9} \\
= & 79.618
\end{array}
$$

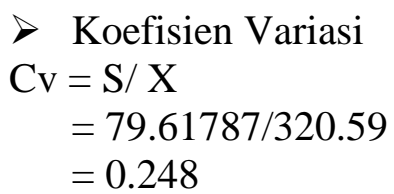

$>$ Koefisien Kemencengan $(\mathrm{Cs})$

$$
\begin{aligned}
\mathrm{Cs} & =\frac{\mathrm{n} \cdot \sum(\mathrm{Xi}-\mathrm{X})^{3}}{(\mathrm{n}-1) \cdot(\mathrm{n}-2) \cdot \mathrm{s}^{3}} \\
& =\frac{10 \times 782203.78}{(10-1) \times(10-2) \times(79.61787)^{3}} \\
& =0.215
\end{aligned}
$$

Koefisien Kurrtosis (Ck)

$$
\begin{aligned}
\mathrm{Ck} & =\frac{\mathrm{n} \sum_{\mathrm{i}=1}\left(\mathrm{Xi}-\mathrm{X}^{4}\right.}{(\mathrm{n}-1)(\mathrm{in}-2)(\mathrm{n}-3) \mathrm{s}} \\
& =\frac{15 \times(685581040)^{4}}{(10-1) \times(10-2) \times(10-3)} \times(79.618) \\
& =0.339
\end{aligned}
$$

Tabel 3. Rekap hasil perhitungan hujan rencana periode ulang metode Gumbel

\begin{tabular}{|c|c|c||}
\hline Tr (tahun) & $\mathbf{Y}_{\mathbf{T r}}$ & $\mathbf{X}_{\mathbf{T r}}(\mathbf{m m})$ \\
\hline 2 & 0.3665 & 309.800 \\
\hline 5 & 1.4999 & 404.828 \\
\hline 10 & 2.2502 & 462.133 \\
\hline 25 & 3.1985 & 547.245 \\
\hline
\end{tabular}

\section{Catchment Area}

Luas daerah tangkapan air (Catchment Area) adalah daerah pengaliran yang menerima curah hujan selama waktu tertentu (Intensitas Hujan) sehingga 
menimbulkan debit limpasan yang harus ditampung oleh saluran hingga mengalir ke ujung saluran (outlet).

\begin{tabular}{|c|c|c|c|c|}
\hline \multirow{2}{*}{\multicolumn{5}{|c|}{ Catchment Area Segmen I }} \\
\hline \multirow{2}{*}{\multicolumn{5}{|c|}{9940400}} \\
\hline & & & & \\
\hline \multicolumn{5}{|l|}{9940300} \\
\hline \multicolumn{5}{|l|}{9940200} \\
\hline \multicolumn{5}{|l|}{9940100} \\
\hline \multicolumn{5}{|l|}{9940000} \\
\hline \multirow{2}{*}{\multicolumn{5}{|c|}{$\begin{array}{rllllll}9939900 & & & & & & \\
511600 & 511650 & 511700 & 511750 & 511800 & 511850 & 511900\end{array}$}} \\
\hline & & $511700 \quad 511750$ & $511800 \quad 5118$ & 850511900 \\
\hline \multicolumn{5}{|c|}{$\multimap$ Series 1} \\
\hline $\bar{X}$ & & $\bar{Y}$ & $\mathbf{X}_{\mathrm{N}} \mathbf{Y}_{\mathrm{N}+\mathbf{1}}$ & $\overline{X_{N+1} Y_{N}}$ \\
\hline 511845,328 & & 9940331,944 & $5,0879 \mathrm{E}+12$ & $5,0858 \mathrm{E}+12$ \\
\hline 511633,726 & & 9940301,821 & $5,0856 \mathrm{E}+12$ & $5,0859 \mathrm{E}+12$ \\
\hline 511643,047 & & 9939999,847 & $5,0857 \mathrm{E}+12$ & $5,0878 \mathrm{E}+12$ \\
\hline 511853,418 & & 9940013,221 & $5,088 \mathrm{E}+12$ & $5,0877 \mathrm{E}+12$ \\
\hline 511845,328 & & 9940331,944 & 0 & 0 \\
\hline & & & & \\
\hline \multicolumn{3}{|c|}{ JUMLAH } & $2,0347 \mathrm{E}+13$ & $2,0347 \mathrm{E}+13$ \\
\hline \multirow{2}{*}{\multicolumn{3}{|c|}{ LUAS AREA }} & 65668,676 & $\mathrm{M}^{2}$ \\
\hline & & & 6,57 & $\mathrm{Ha}$ \\
\hline
\end{tabular}

\section{Catchment Area Segmen II}

\begin{tabular}{|c|c|c|c|}
\hline 9940100 \\
9940000 \\
9939900 \\
9939700 \\
9939600 \\
9939500 \\
5151650
\end{tabular}




\section{Area Segmen III}

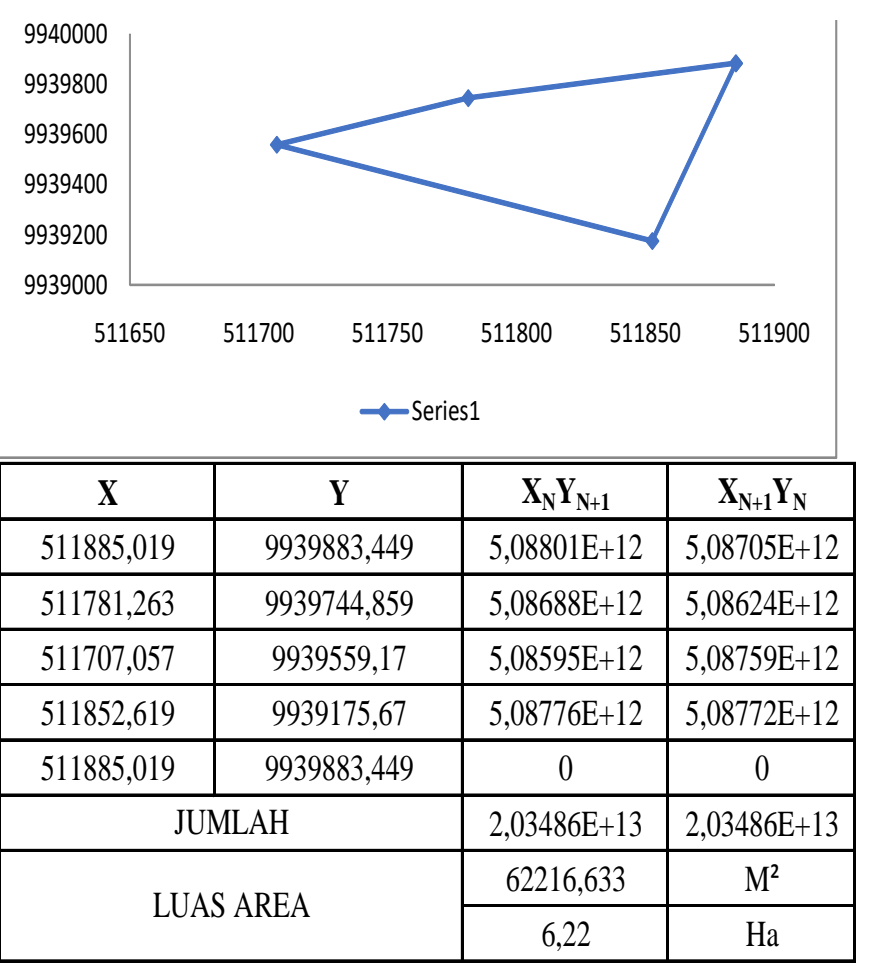

\section{Perhitungan Debit Aliran}

$\mathrm{Q}=0.278$ C.I.A

$=0.278 \times 0.411 \times 352,67 \times 0.066$

$=2.643 \mathrm{~m}^{3} / \mathrm{dtk}$

Tabel 4. Perhitungan debit aliran pada periode 5 tahun

\begin{tabular}{|l|l|l|l|l|l|}
\hline Saluran & Menuju & $\mathbf{C}$ & $\mathbf{I}(\mathbf{m} / \mathbf{d e t})$ & $\mathbf{A}\left(\mathbf{m}^{\mathbf{2}}\right)$ & $\begin{array}{l}\text { Qah } \\
\left(\mathbf{m}^{\mathbf{3}} / \mathbf{d t}\right)\end{array}$ \\
\hline Segmen 1 & Pembuangan & 0.411 & 0.0001280 & 65668 & 0.959 \\
\hline segmen 2 & Pembuangan & 0.604 & 0.0001331 & 62156 & 1.389 \\
\hline segmen 3 & Pembuangan & 0.603 & 0.0001374 & 62216 & 1.434 \\
\hline
\end{tabular}

Tabel 5. Perhitungan debit aliran pada periode 10 tahun

\begin{tabular}{|l|l|l|l|l|l|}
\hline Saluran & Menuju & $\mathbf{C}$ & $\mathbf{I}(\mathbf{m} / \mathbf{d e t})$ & $\mathbf{A}\left(\mathbf{m}^{\mathbf{2}}\right)$ & $\begin{array}{l}\text { Qah } \\
\left(\mathbf{m}^{3} / \mathbf{d t}\right)\end{array}$ \\
\hline Segmen 1 & Pembuangan & 0.411 & 0.0001479 & 65668 & 1.108 \\
\hline segmen 2 & Pembuangan & 0.600 & 0.0001558 & 62156 & 1.605 \\
\hline segmen 3 & Pembuangan & 0.603 & 0.0001588 & 62216 & 1.657 \\
\hline
\end{tabular}

Tabel 6. Perhitungan debit aliran pada periode 25 tahun

\begin{tabular}{|l|l|l|l|l|l|}
\hline Saluran & Menuju & C & I (m/det) & $\mathbf{A}\left(\mathbf{m}^{2}\right)$ & $\begin{array}{l}\text { Qah } \\
\left(\mathbf{m}^{3} / \mathbf{d t}\right)\end{array}$ \\
\hline Segmen 1 & Pembuangan & 0.411 & 0.0001730 & 65668 & 1.297 \\
\hline
\end{tabular}




\begin{tabular}{|l|l|l|l|l|l|} 
segmen 2 & Pembuangan & 0.604 & 0.0001800 & 62156 & 1.878 \\
\hline segmen 3 & Pembuangan & 0.603 & 0.0001858 & 62216 & 1.938 \\
\hline
\end{tabular}

\section{Perhitungan Kapasitas Saluran Drainase Existing}

$$
\begin{aligned}
\mathrm{A} & =\mathrm{b} \times \mathrm{y} \\
& =1.42 \times 0.5 \\
& =0.71 \mathrm{~m}^{2} \\
\mathrm{P} & =\mathrm{b}+2 \mathrm{y} \\
& =1.42+(2 \times 0.5) \\
& =2.42 \mathrm{~m} \\
\mathrm{R} & =\frac{\mathrm{by}}{\mathrm{b}+2 \mathrm{y}} \\
& =\frac{0.71 \mathrm{~m}^{2}}{2.42 \mathrm{~m}} \\
& =0.293 \mathrm{~m}
\end{aligned}
$$

$$
\begin{aligned}
T c & =0.0195\left(\frac{L s}{S^{1 / 2}}\right)^{0.77} \\
s & =\left(\frac{L s^{0.77}}{T c / 0.0195}\right)^{1 / 1.27} \\
s & =\left(\frac{300^{0.77}}{(10,08 / 0.0195)}\right)^{1 / 1.27} \\
& =0.232
\end{aligned}
$$

$$
\begin{aligned}
\mathrm{Q} & =\mathrm{A} . \mathrm{V} \\
& =0,71 \mathrm{~m}^{2} \times\left(1 / \mathrm{nR}^{2 / 3} \cdot \mathrm{S}^{1 / 2}\right) \\
& =0,71 \mathrm{~m}^{2} \times\left(1 / 0.13 \times 0.293^{2 / 3} \times 0.2232^{1 / 2}\right) \\
& =0,7342 \mathrm{~m}^{3} / \mathrm{dtk}
\end{aligned}
$$

Penampang Saluran Segiempat pada segmen 1

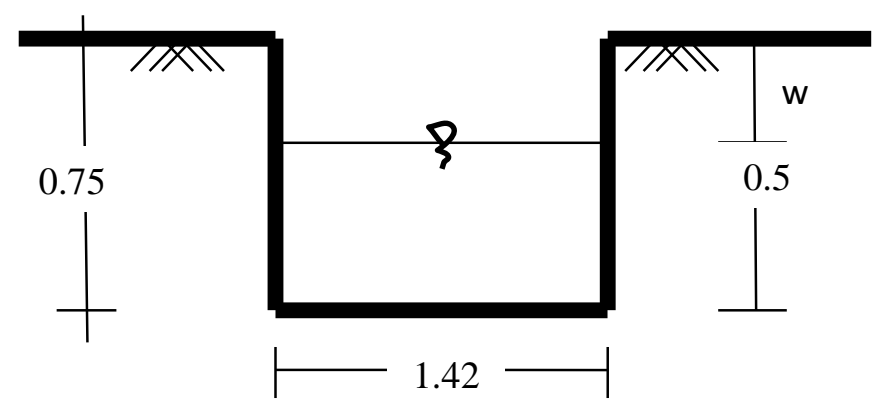

Gambar 1. Penampang saluran segmen 1

Penampang Saluran Segiempat pada segmen 2

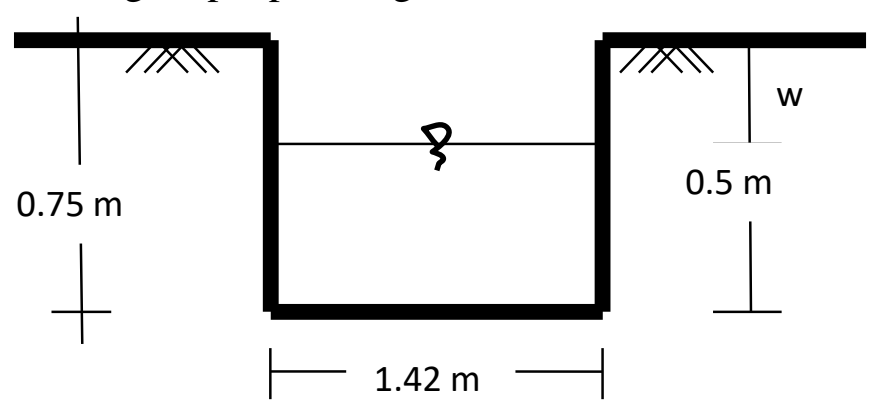

Gambar 2. Penampang saluran segmen 2 
Penampang Saluran Segiempat pada segmen 3

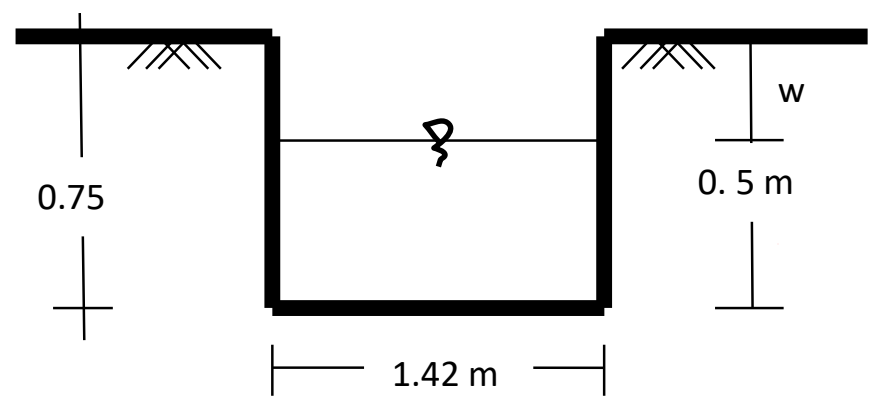

Gambar 3. Penampang saluran segmen 3

\section{Perhitungan Kapasitas Saluran Drainase Existing}

Tabel 7. Perhitungan Kapasitas Saluran Drainase Pada Periode 5 Tahun

\begin{tabular}{|c|c|c|c|c|c|c|c|c|c|c|c|}
\hline \multirow{2}{*}{ Saluran } & \multicolumn{9}{|c|}{ Dimensi Existing } & \multirow{2}{*}{$\begin{array}{l}\text { debit } \\
\text { rancangan } \\
5 \text { tahun } \\
\left(\mathrm{m}^{3} / \mathrm{dt}\right)\end{array}$} & \multirow{2}{*}{ Ket. } \\
\hline & $\mathbf{b}(\mathbf{m})$ & $\mathbf{h}(\mathbf{m})$ & $\mathbf{y}(\mathbf{m})$ & $\mathbf{A}\left(\mathbf{m}^{2}\right)$ & $\mathbf{P}(\mathbf{m})$ & $\mathbf{R}(\mathbf{m})$ & $\mathbf{n}$ & $\mathbf{S}$ & $Q\left(m^{3} / d t\right)$ & & \\
\hline Segmen 1 & 1.42 & 0.75 & 0.5 & 0.71 & 2.42 & 0.293 & 0.13 & 0.232 & 1.1611 & 0.959 & Cukup \\
\hline Segmen 2 & 1.42 & 0.75 & 0.5 & 0.71 & 2.42 & 0.293 & 0.13 & 0.190 & 1.0509 & 1.389 & $\begin{array}{l}\text { Tidak } \\
\text { Mencukupi }\end{array}$ \\
\hline Segmen 3 & 1.42 & 0.75 & 0.5 & 0.71 & 2.42 & 0.293 & 0.13 & 0.166 & 0.9814 & 1.434 & $\begin{array}{l}\text { Tidak } \\
\text { Mencukupi }\end{array}$ \\
\hline
\end{tabular}

Tabel 8. Perhitungan Kapasitas Saluran Drainase Pada Periode 10 Tahun

\begin{tabular}{|c|c|c|c|c|c|c|c|c|c|c|c|}
\hline \multirow{2}{*}{ Saluran } & \multicolumn{9}{|c|}{ Dimensi Existing } & \multirow{2}{*}{$\begin{array}{l}\text { debit } \\
\text { rancangan } \\
10 \text { tahun } \\
\left(\mathbf{m}^{3} / \mathbf{d t}\right)\end{array}$} & \multirow{2}{*}{ Ket. } \\
\hline & $\mathbf{b}(\mathbf{m})$ & $\mathbf{h}(\mathbf{m})$ & $\mathbf{y}(\mathbf{m})$ & $\mathbf{A}\left(\mathbf{m}^{2}\right)$ & $\mathbf{P}(\mathbf{m})$ & $\mathbf{R}(\mathbf{m})$ & n & $\mathbf{S}$ & $\begin{array}{c}Q \\
\left(\mathbf{m}^{3} / \mathrm{dt}\right)\end{array}$ & & \\
\hline Segmen 1 & 1.42 & 0.75 & 05 & 0.71 & 2.42 & 0.293 & 0.13 & 0.232 & 1.1611 & 1.108 & Cukup \\
\hline Segmen 2 & 1.42 & 0.75 & 0.5 & 0.71 & 2.42 & 0.293 & 0.13 & 0.190 & 1.0509 & 1.605 & $\begin{array}{l}\text { Tidak } \\
\text { Mencukupi }\end{array}$ \\
\hline Segmen 3 & 1.42 & 0.75 & 0.5 & 0.71 & 2.42 & 0.293 & 0.13 & 0.166 & 0.9814 & 1.657 & $\begin{array}{l}\text { Tidak } \\
\text { Mencukupi }\end{array}$ \\
\hline
\end{tabular}

Tabel 9. Perhitungan Kapasitas Saluran Drainase Pada Periode 25 Tahun

\begin{tabular}{|c|c|c|c|c|c|c|c|c|c|c|c|}
\hline \multirow{2}{*}{ Saluran } & \multicolumn{9}{|c|}{ Dimensi Existing } & \multicolumn{1}{|c|}{$\begin{array}{l}\text { debit } \\
\text { rancangan } \\
\mathbf{2 5} \begin{array}{c}\text { tahun } \\
\left(\mathbf{m}^{3} / \mathbf{d t}\right)\end{array}\end{array}$} & \multirow{2}{*}{ Ket. } \\
\cline { 2 - 13 } & $\mathbf{b}(\mathbf{m})$ & $\mathbf{h}(\mathbf{m})$ & $\mathbf{y}(\mathbf{m})$ & $\mathbf{A}\left(\mathbf{m}^{2}\right)$ & $\mathbf{P}(\mathbf{m})$ & $\mathbf{R}(\mathbf{m})$ & $\mathbf{n}$ & $\mathbf{S}$ & $\mathbf{Q}\left(\mathbf{m}^{3} / \mathbf{d t}\right)$ & 1.297 & $\begin{array}{l}\text { Tidak } \\
\text { mencukupi }\end{array}$ \\
\hline Segmen 1 & 1.42 & 0.75 & 0.5 & 0.71 & 2.42 & 0.293 & 0.13 & 0.232 & 1.1611 & 1.878 & $\begin{array}{l}\text { Tidak } \\
\text { Mencukupi }\end{array}$ \\
\hline Segmen 2 & 1.42 & 0.75 & 0.5 & 0.71 & 2.42 & 0.293 & 0.13 & 0.190 & 1.0509 & 1.938 & $\begin{array}{l}\text { Tidak } \\
\text { mencukupi }\end{array}$ \\
\hline Segmen 3 & 1.42 & 0.75 & 0.5 & 0.71 & 2.42 & 0.293 & 0.13 & 0.166 & 0.9814 & 1.938 \\
\hline
\end{tabular}


JURNAL KACAPURI

JURNAL KEILMUAN TEKNIK SIPIL

Volume 3 Nomor 2 Edisi Desember 2020

Tabel 10. Perhitungan Kapasitas Saluran Drainase Rencana Pada Periode 5

Tahun

\begin{tabular}{|c|c|c|c|c|c|c|c|c|c|c|c|}
\hline \multirow{2}{*}{ Saluran } & \multicolumn{9}{|c|}{ Dimensi Rencana } & \multirow{2}{*}{$\begin{array}{l}\text { debit } \\
\text { rancangan } \\
5 \text { tahun } \\
\left(\mathbf{m}^{3} / \mathbf{d t}\right) \\
\end{array}$} & \multirow{2}{*}{ Ket } \\
\hline & $\mathbf{b}(\mathbf{m})$ & $\mathbf{h}(\mathbf{m})$ & $\mathbf{y}(\mathbf{m})$ & $\mathbf{A}\left(\mathbf{m}^{2}\right)$ & $\mathbf{P}(\mathbf{m})$ & $\mathbf{R}(\mathbf{m})$ & $\mathbf{n}$ & $\mathbf{S}$ & $\mathbf{Q}\left(\mathbf{m}^{3} / \mathbf{d t}\right)$ & & \\
\hline Segmen 1 & 1.5 & 1.2 & 0.7 & 1.05 & 2.9 & 0.362 & 0.13 & 0.232 & 1.9756 & 0.959 & Cukup \\
\hline Segmen 2 & 1.5 & 1.2 & 0.7 & 1.05 & 2.9 & 0.362 & 0.13 & 0.190 & 1.7881 & 1.389 & Cukup \\
\hline Segmen 3 & 1.5 & 1.2 & 0.7 & 1.05 & 2.9 & 0.362 & 0.13 & 0.166 & 1.6699 & 1.434 & Cukup \\
\hline Segmen 4 & 1.5 & 1.2 & 0.7 & 1.05 & 2.9 & 0.362 & 0.13 & 0.179 & 1.7362 & 1.078 & Cukup \\
\hline Segmen 5 & 1.5 & 1.2 & 0.7 & 1.05 & 2.9 & 0.362 & 0.13 & 0.114 & 1.3844 & 0.604 & Cukup \\
\hline Segmen 6 & 1.5 & 1.2 & 0.7 & 1.05 & 2.9 & 0.362 & 0.13 & 0.162 & 1.6503 & 0.972 & Cukup \\
\hline
\end{tabular}

Tabel 11. Perhitungan Kapasitas Saluran Drainase Rencana Pada Periode 10

Tahun

\begin{tabular}{|c|c|c|c|c|c|c|c|c|c|c|c|}
\hline \multirow{2}{*}{ Saluran } & \multicolumn{9}{|c|}{ Dimensi Rrencana } & \multirow{2}{*}{$\begin{array}{l}\text { debit } \\
\text { rancangan } \\
10 \text { tahun } \\
\left(\mathrm{m}^{3} / \mathrm{dt}\right)\end{array}$} & \multirow{2}{*}{ Ket. } \\
\hline & $\mathbf{b}(\mathbf{m})$ & $\mathbf{h}(\mathbf{m})$ & $\mathbf{y}(\mathbf{m})$ & $\mathbf{A}\left(\mathbf{m}^{2}\right)$ & $\mathbf{P}(\mathbf{m})$ & $\mathbf{R}(\mathbf{m})$ & $\mathbf{n}$ & $\mathbf{S}$ & $Q\left(\mathbf{m}^{3} / \mathbf{d t}\right)$ & & \\
\hline Segmen 1 & 1.5 & 1.3 & 0.7 & 1.05 & 2.9 & 0.362 & 0.13 & 0.232 & 1.9756 & 1.108 & Cukup \\
\hline Segmen 2 & 1.5 & 1.3 & 0.7 & 1.05 & 2.9 & 0.362 & 0.13 & 0.190 & 1.7881 & 1.605 & Cukup \\
\hline Segmen 3 & 1.5 & 1.3 & 0.7 & 1.05 & 2.9 & 0.362 & 0.13 & 0.166 & 1.6699 & 1.657 & Cukup \\
\hline Segmen 4 & 1.5 & 1.3 & 0.7 & 1.05 & 2.9 & 0.362 & 0.13 & 0.179 & 1.7368 & 1.246 & Cukup \\
\hline Segmen 5 & 1.5 & 1.3 & 0.7 & 1.05 & 2.9 & 0.362 & 0.13 & 0.114 & 1.3844 & 0.698 & Cukup \\
\hline Segmen 6 & 1.5 & 1.3 & 0.7 & 1.05 & 2.9 & 0.362 & 0.13 & 0.162 & 1.6503 & 1.123 & Cukup \\
\hline
\end{tabular}

Tabel 11. Perhitungan Kapasitas Saluran Drainase Rencana Pada Periode 25

Tahun

\begin{tabular}{|c|c|c|c|c|c|c|c|c|c|c|c|}
\hline \multirow{2}{*}{ Saluran } & \multicolumn{9}{|c|}{ Dimensi Rencana } & \multirow{2}{*}{$\begin{array}{l}\text { debit } \\
\text { rancangan } \\
25 \text { tahun } \\
\left(\mathrm{m}^{3} / \mathrm{dt}\right)\end{array}$} & \multirow{2}{*}{ Ket. } \\
\hline & $\mathbf{b}(\mathbf{m})$ & $\mathbf{h}(\mathbf{m})$ & $\mathbf{y}(\mathbf{m})$ & $\mathbf{A}\left(\mathbf{m}^{2}\right)$ & $\mathbf{P}(\mathbf{m})$ & $\mathbf{R}(\mathbf{m})$ & $\mathbf{n}$ & $\mathbf{S}$ & $Q\left(\mathbf{m}^{3} / \mathbf{d t}\right)$ & & \\
\hline Segmen 1 & 1.5 & 1.4 & 0.8 & 1.2 & 3.1 & 0.387 & 0.13 & 0.232 & 2.3608 & 1.297 & Cukup \\
\hline Segmen 2 & 1.5 & 1.4 & 0.8 & 1.2 & 3.1 & 0.387 & 0.13 & 0.190 & 2.1366 & 1.878 & cukup \\
\hline Segmen 3 & 1.5 & 1.4 & 0.8 & 1.2 & 3.1 & 0.387 & 0.13 & 0.166 & 1.9954 & 1.938 & Cukup \\
\hline Segmen 4 & 1.5 & 1.4 & 0.8 & 1.2 & 3.1 & 0.387 & 0.13 & 0.179 & 2.0754 & 1.458 & Cukup \\
\hline Segmen 5 & 1.5 & 1.4 & 0.8 & 1.2 & 3.1 & 0.387 & 0.13 & 0.114 & 1.6542 & 0.817 & Cukup \\
\hline Segmen 6 & 1.5 & 1.4 & 0.8 & 1.2 & 3.1 & 0.387 & 0.13 & 0.162 & 1.9720 & 1.314 & Cukup \\
\hline
\end{tabular}


Penampang Saluran Segiempat pada segmen 1 (Dimensi Rencana)

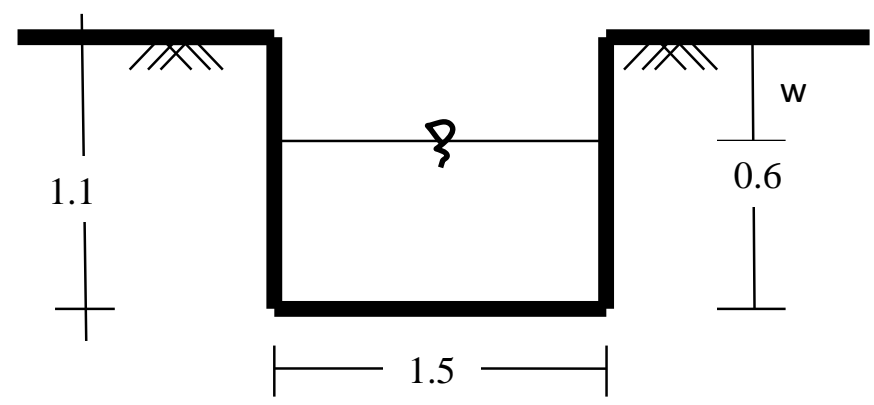

Gambar 4. Penampang saluran segmen 1

Penampang Saluran Segiempat pada segmen 2 (Dimensi Rencana)

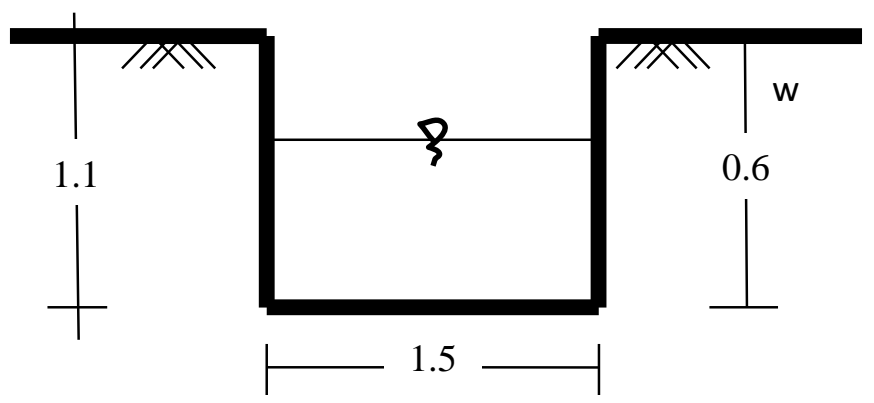

Gambar 5. Penampang saluran segmen 2

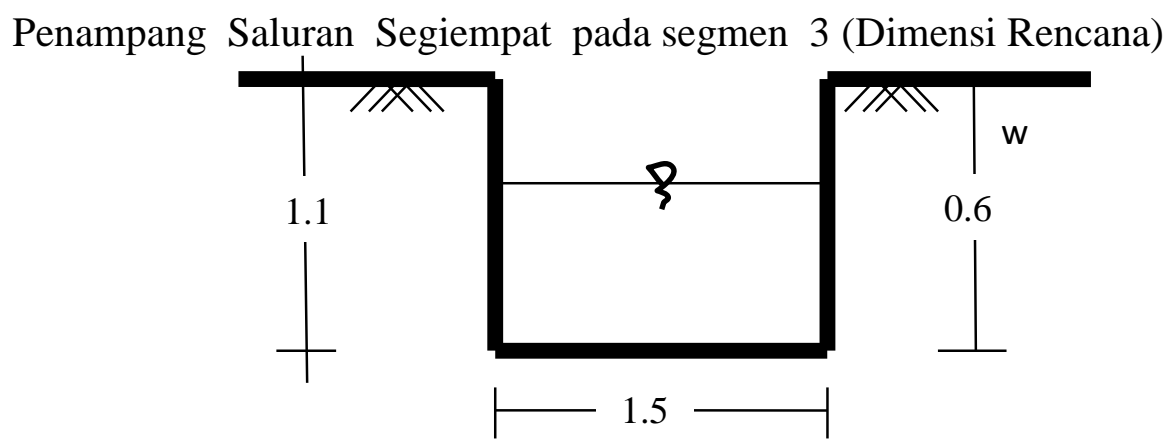

Gambar 6. Penampang saluran segmen 3

\section{PENUTUP}

\section{Kesimpulan}

Dari hasil analisa dan perhitungan didapat kesimpulan sebagai berikut :

1. Kapasitas debit air (Q) saluran existing di jalan Kebun Agung Samarinda pada segmen satu $1.1611 \mathrm{~m}^{3} / \mathrm{dt}$, segmen dua $1.0509 \mathrm{~m}^{3} / \mathrm{dt}$ dan segmen tiga $0.9814 \mathrm{~m}^{3} / \mathrm{dt}$. 
2. Kapasitas debit air yang diperlukan pada saluran drainase rencana dapat dilihat pada tabel 12 dan dimensi rencana pada tabel 13 sebagai berikut :

Tabel 11 Rekapan kapasitas debit air rencana

\begin{tabular}{|l|l|c|c|c|}
\hline \multicolumn{2}{|c|}{ Saluran } & \multicolumn{3}{c|}{ Kala Ulang } \\
\cline { 3 - 5 } Segmen 1 & Q (m3/dt) & 1.9756 & 1.9756 & 2.3602 \\
\hline Segmen 2 & Q (m3/dt) & 1.7881 & 1.7881 & 2.1366 \\
\hline Segmen 3 & Q (m3/dt) & 1.6699 & 1.6699 & 1.9954 \\
\hline
\end{tabular}

Tabel 12 Dimensi rencana drainase

\begin{tabular}{|l|l|c|c|c|}
\hline \multirow{2}{*}{ Saluran } & \multicolumn{3}{|c|}{ Kala Ulang } \\
\cline { 3 - 5 } & & 5 & 10 & 25 \\
\hline \multirow{2}{*}{ Segmen 1 } & Lebar $(\mathrm{m})$ & 1.5 & 1.5 & 1.5 \\
\cline { 2 - 5 } & Tinggi $(\mathrm{m})$ & 1.2 & 1.3 & 1.4 \\
\hline \multirow{2}{*}{ Segmen 2 } & Lebar $(\mathrm{m})$ & 1.5 & 1.5 & 1.5 \\
\cline { 2 - 5 } & Tinggi $(\mathrm{m})$ & 1.2 & 1.3 & 1.4 \\
\hline \multirow{2}{*}{ Segmen 3 } & Lebar $(\mathrm{m})$ & 1.5 & 1.5 & 1.5 \\
\cline { 2 - 5 } & Tinggi $(\mathrm{m})$ & 1.2 & 1.3 & 1.4 \\
\hline
\end{tabular}

\section{Saran}

1. Melaksanakan penelitian lanjutan dengan menambah variabel perencanaan struktur saluran drainase.

2. Melakukan perawatan saluran drainase sekitar 4 bulan sekali, agar pertumbuhan gulma dapat dihambat serta melakukan pengerukan agar tidak terjadi proses sedimentasi karena dikhawatirkan kedalaman saluran drainase menjadi dangkal.

\section{DAFTAR PUSTAKA}

1. Adidarma, W, dkk. Pola Hujan Jam - Jaman untuk Perhitungan Banjir Rencana. Puslitbang SDA Kementrian PU.

2. Bedient P. B dan Huber W. C. 1992. Hydrology and Floodplain Analysis. Addison - Wesley Publishing Company.

3. Chow, V. T, dkk. 1988. Applied Hydrology. Mc Graw - Hill International.

4. Hindarko, S.2010. Drainase Perkotaan (Seri Lingkungan Hidup). Penerbit Andi, Yogyakarta.

5. Kodoatie, R. J dan Sugiyanto. 2002. Banjir (Beberapa Penyebab dan Metode Pengendaliannya dalam Perspektif Lingkungan). Pustaka Pelajar, Yogyakarta.

6. Linsley Jr, R. K, dkk. 1996. Hidrologi untuk Insinyur. Erlangga, Jakarta.

7. Soemarto, C. D. 1999. Hidologi Teknik. Erlangga, Jakarta.

8. Sri Harto, Br. 1993. Analisis Hidrologi. Penerbit PT Gramedia Pustaka Utama, Jakarta.

9. Wesly. 2008. Drainase Perkotaan. Graha Ilmu Yogyakarta. 